\title{
Salvage cytoreductive surgery for patients with recurrent endometrial cancer: a retrospective study
}

\author{
Yulan Ren ${ }^{1,2}$, Boer Shan ${ }^{1,2}$, Daren Shi ${ }^{1,3}$ and Huaying Wang ${ }^{1,2^{*}}$
}

\begin{abstract}
Background: Salvage cytoreductive surgery (SCR) has been shown to improve the survival of cancer patients. This study aimed to determine the survival benefits of SCR for recurrent endometrial cancer in Chinese population.

Methods: Between January 1995 and May 2012, 75 Chinese patients with recurrent endometrial cancer undergoing SCR were retrospectively analyzed.

Results: 43 patients (57.3\%) had RO (no visible disease), 15 patients (20.0\%) had R1 (residual disease $\leq 1 \mathrm{~cm}$ ), and 17 (22.7\%) had R2 (residual disease $>1 \mathrm{~cm}$ ) Resection. 35 patients (46.7\%) had single, and 40 (53.3\%) had multiple sites of recurrence. The median survival time was 18 months, and 5-year overall survival (OS) rate were $42.0 \%$. Multivariate analysis showed that residual disease $\leq 1 \mathrm{~cm}$ and high histology grade were significantly associated with a better OS. The size of the largest recurrent tumors $(\leq 6 \mathrm{~cm}$ ), solitary recurrent tumor, and age at recurrence ( $\leq 56$ years old) were associated with optimal SCR.

Conclusion: Optimal SCR and high histology grade are associated with prolonged overall survival for patients with recurrent endometrial cancer. Patients with young age, tumor size $<6 \mathrm{~cm}$, and solitary recurrent tumor are more likely to benefit from optimal cytoreductive surgery.
\end{abstract}

Keywords: Endometrial cancer, Recurrence, Cytoreductive surgery, Prognosis

\section{Background}

Endometrial carcinoma is a common gynecological cancer and the majority of patients present at an early stage with a good long-term prognosis. However, about $13 \%$ of patients with endometrial cancer develop recurrent disease, and they have a very poor outcome with a mortality of about $25 \%[1,2]$.

Treatment options for recurrent endometrial cancer vary according to the distribution of recurrent disease. Chemotherapy is often recommended for patients with distant or widely metastatic recurrences, while radiotherapy is recommended for patients with small, isolated pelvic recurrences who have not received radiation [3,4]. For surgery, pelvic exenteration is recommended for the treatment of a localized central pelvic recurrence refractory to radiation therapy $[5,6]$, while the benefit

\footnotetext{
* Correspondence: huaying_wang@yahoo.com

'Department of Gynecologic Oncology, Fudan University Shanghai Cancer

Center, Shanghai 200032, China

2Department of Oncology, Shanghai Medical College, Fudan University,

Shanghai 200032, China

Full list of author information is available at the end of the article
}

of salvage cytoreductive surgery (SCR) in patients with recurrent endometrial cancer is not confirmed. Several recent reports reported that selected patients with resectable recurrent endometrial cancer could benefit from complete SCR [7-10]. Therefore, the surgical indications and selection criteria are urgently needed to minimize the complications and mortality associated with surgery.

In this retrospective study, we evaluated the survival benefit and the safety of SCR for Chinese patients with recurrent endometrial cancer, and tried to define the selection indications for SCR.

\section{Methods}

Ethics statement

The study was approved by Ethics Committee of Fudan University. All patients who participated in the study signed informed consent forms.

\section{Study design}

All patients with recurrent endometrial cancer undergoing second SCR at the Department of Gynecologic Oncology 
at Fudan University Shanghai Cancer Center (FUSCC) between January 1995 and May 2012 were identified from a search of FUSCC Endometrial Cancer database. Patients with nonepithelial tumors (eg. sarcoma) were excluded. Recurrence was defined as a regrowth of tumor at least 3 months after the completion of primary therapy.

Patient data were abstracted retrospectively from inpatient and outpatient medical records, including clinical, surgery, and pathology reports of both primary and secondary surgeries. All patients were restaged by the International Federation of Gynecology and Obstetrics (FIGO) stage 2009 [11]. Progression free interval (PFI) was defined as the time from primary surgery to the diagnosis of recurrence. The level of cytoreduction for recurrent endometrial cancer was defined as: R0, complete resection with no visible disease; $R 1$, residual disease $\leq 1 \mathrm{~cm}$; $R 2$, residual disease $>1 \mathrm{~cm}$.

The recurrent sites were categorized as solitary and multiple. Patients were divided into two groups according to the detection of recurrence: symptomatic, and asyptomatic groups.

All patients were followed up at least 3 months after surgery. Two patients died 2 months after SCR, and one patients lost follow-up after hospital discharge. The median follow-up duration was 18 months (range: 2-112 months).

\section{Statistical analysis}

The primary statistical endpoints were overall survival (OS) calculated from the date of SCR to the date of death or last follow-up and progression-free survival (PFS) from the date of SCR to the date of progression of disease. The chi-square test was used for discrete and binomial data. Stepwise logistic regression was used to analyze the correlations between clinico-pathological variables and SCR outcome. Survival curves were estimated by Kaplan-Meier method and compared using the log-rank test. Multivariate analysis was performed by Cox proportional hazards regression model. $P<0.05$ was set to be significant. All statistical analyses were performed using SPSS software (version 11.0).

\section{Results}

\section{Patient characteristics}

Total 75 patients with recurrent endometrial cancer who underwent surgery during the study period were identified. Clinico-pathological characteristics were summarized in Table 1. Median age at the first surgery was 55 years old (range: $31-75)$. At the first surgery, 53 (70.7\%) patients had stage I disease (FIGO 2009), 5 (6.7\%) had stage II, 13 (17.3\%) had stage III, and 4 (5.3\%) had stage IV disease. Sixty-five (85.7\%) patients were diagnosed with endometrioid adenocarcinoma, and 10 (13.3\%) patients with non-endometrioid adenocarcinoma, including
6 papillary serous cancer, 3 clear cell cancer, and 1 squamous cell cancer.

At the first surgery, ECOG scores were no more than 2, including 0 in 6 patients, 1 in 62 patients, and 2 in 7 patients. Twenty-seven (36.0\%) patients received total hysterectomy with bilateral salpingoopherectomy (TH/BSO), $10(13.3 \%)$ received radical hysterectomy with bilateral salpingoopherectomy (RH/BSO), 12 (16.0\%) received $\mathrm{TH} / \mathrm{BSO}$ and pelvic lymphadenectomy (PL), 15 (20.0\%) received $\mathrm{RH} / \mathrm{BSO} / \mathrm{PL}, 4(5.3 \%)$ received $\mathrm{TH} / \mathrm{BSO} / \mathrm{PL}$ and para-aortic lymphadenectomy, 7 (9.3\%) received $\mathrm{TH} /$ BSO and cytoreduction surgery. For patients requiring primary cytoreductive surgery, an optimal resection was obtained in all patients. After the first surgery, 48 (64\%) patients received adjuvant therapy, including 33 (44.0\%) patients with chemotherapy, 5 (6.7\%) with radiotherapy, $6(8.0 \%)$ with both chemotherapy and radiotherapy, and $4(5.3 \%)$ with hormonal therapy.

Median PFI was 18 months (range: 3-372). Median age at recurrence was 56 years old (range: 33-76). In recurrence, 30 patients were diagnosed without symptoms at routine follow-up, and 45 patients with various symptoms, including vaginal bleeding or discharge (17 cases), abdominal pain (16 cases), inguinal mass (3 cases), lowdegree fever (3 cases), constipation (3 cases), diarrhea (1 case), hemoptysis (1 case), and lower limb edema (1 case).

Before SCR, 24 cases were treated with chemotherapy, 4 cased with both chemotherapy and radiotherapy, and 1 case with radiotherapy. The most common regimens were paclitaxel plus platinum, or platinum plus doxorubicin.

\section{Salvage cytoreductive surgery}

Characteristics of recurrence and SCR were summarized in Table 2. ECOG scores before SCR were no more than 3 , including 0 in 30 patients, 1 in 25 patients, 2 in 15 patients, and 3 in 5 patients. During SCR, median largest size of recurrence disease was $6 \mathrm{~cm}$ (range: 1-25). Recurrence was found solitary in 35 (46.7\%) patients and multiple in $40(53.3 \%)$ patients. Ascites were found in $8(10.5 \%)$ patients with recurrence, with median ascites volume $450 \mathrm{ml}$ (range: 200-2400 ml). After SCR, 58 (77.3\%) patients achieved optimal cytoreduction (residual disease $\leq 1 \mathrm{~cm})$. Nine $(12.0 \%)$ patients developed perioperative complications, and no patient died during perioperative period.

After SCR, 48 (64.0\%) patients received salvage chemotherapy. The main regimen used was platinum plus taxol (in 29 patients). Six (8.0\%) patients received radiotherapy, and $8(10.7 \%)$ patients received both chemotherapy and radiotherapy. Twenty (26.7\%) patients received hormonal therapy after SCR (5 alone, 15 combined with chemotherapy and/or radiotherapy). 
Table 1 Clinicopathological characteristics of patients and univariate analysis for OS after SCR

\begin{tabular}{|c|c|c|c|c|}
\hline & Cases & Deaths & Median OS (months) & $U V^{a}$ analysis ( $P$ value) \\
\hline Age at second surgery & & & & 0.549 \\
\hline$\leq 56$ years & 38 & 15 & 60 & \\
\hline$>56$ years & 37 & 15 & 39 & \\
\hline ECOG performance status at first surgery & & & & 0.352 \\
\hline 0 & 6 & 1 & 48.00 & \\
\hline 1 & 62 & 25 & 62.124 & \\
\hline 2 & 7 & 4 & 34.00 & \\
\hline Stage at first surgery (FIGO 2009) & & & & 0.760 \\
\hline Stage I-II & 58 & 22 & 65.675 & \\
\hline Stage III-IV & 17 & 8 & 45.159 & \\
\hline Pathological subtype & & & & 0.180 \\
\hline Endometrioid & 65 & 28 & 57.753 & \\
\hline Nonendometrioid & 10 & 2 & 52.10 & \\
\hline \multicolumn{5}{|l|}{ Histological grade } \\
\hline I & 14 & 4 & 67.921 & 0.068 \\
\hline II & 39 & 15 & 68.006 & $0.040^{*}$ \\
\hline III & 22 & 11 & 44.819 & Reference \\
\hline Postoperative therapy after first surgery & & & & 0.309 \\
\hline Chemotherapy & 33 & 14 & 53.51 & \\
\hline Radiotherapy & 5 & 2 & 36 & \\
\hline $\mathrm{CT}+\mathrm{RT}$ & 6 & 1 & 72 & \\
\hline Hormonal therapy & 4 & 1 & 114 & \\
\hline No & 27 & 12 & 36.196 & \\
\hline Symptoms at recurrence & & & & 0.723 \\
\hline Nonsymptomatic & 30 & 13 & 54 & \\
\hline Symptomatic & 45 & 17 & 65 & \\
\hline CA125 at recurrence & & & & 0.108 \\
\hline$\leq 35 \mathrm{U} / \mathrm{ml}$ & 25 & 7 & 69.650 & \\
\hline$>35 \mathrm{U} / \mathrm{ml}$ & 35 & 18 & 35.733 & \\
\hline Not available & 15 & 5 & 77.548 & \\
\hline Recurrence detection of nonsymptomatic & & & & 0.134 \\
\hline Imaging or CA-125 & 17 & 8 & 44.83 & \\
\hline Physical examination & 13 & 4 & 96 & \\
\hline PFI & & & & $0.032^{*}$ \\
\hline$\leq 18$ months & 40 & 19 & 34.963 & \\
\hline$>18$ months & 35 & 11 & 76.078 & \\
\hline Largest size of recurrence & & & & $0.008^{*}$ \\
\hline$\leq 6 \mathrm{~cm}$ & 36 & 10 & 79.027 & \\
\hline$>6 \mathrm{~cm}$ & 39 & 20 & 35.918 & \\
\hline Multiplicity of recurrence & & & & 0.144 \\
\hline Solitary & 35 & 12 & 73.219 & \\
\hline Multiple & 40 & 18 & 37.295 & \\
\hline Site of recurrence & & & & 0.056 \\
\hline Pelvis $^{b}$ and/or introabdomonal & 63 & 23 & 66.186 & \\
\hline Retroperitoneal & 12 & 7 & 30.380 & \\
\hline
\end{tabular}


Table 1 Clinicopathological characteristics of patients and univariate analysis for OS after SCR (Continued)

\begin{tabular}{|c|c|c|c|c|}
\hline Ascites & & & & $0.048^{*}$ \\
\hline None & 67 & 26 & 64.678 & \\
\hline Yes & 8 & 4 & 17.171 & \\
\hline ECOG performance status before SCR & & & & 0.311 \\
\hline 0 & 30 & 13 & 53.28 & \\
\hline 1 & 26 & 9 & 109.31 & \\
\hline 2 & 14 & 5 & 72.0 & \\
\hline 3 & 5 & 3 & 14.4 & \\
\hline \multicolumn{5}{|l|}{ Residual disease after SCR } \\
\hline None & 43 & 12 & 76.462 & $0.000^{*}$ \\
\hline $0.1 \sim 1 \mathrm{~cm}$ & 15 & 6 & 43.825 & $0.001^{*}$ \\
\hline $1 \sim 2 \mathrm{~cm}$ & 6 & 4 & 30.833 & 0.207 \\
\hline$>2 \mathrm{~cm}$ & 11 & 8 & 12.778 & Reference \\
\hline \multicolumn{5}{|l|}{ Postoperative therapy after SCR } \\
\hline Chemotherapy & 48 & 22 & 40.192 & Reference \\
\hline Radiotherapy & 6 & 1 & 114.0 & $0.045^{*}$ \\
\hline $\mathrm{CT}+\mathrm{RT}$ & 8 & 3 & 42.0 & 0.764 \\
\hline No & 13 & 4 & 72.0 & 0.615 \\
\hline
\end{tabular}

Note. a, UV, univariate; b, pelvis: including inguinal and vaginal; CT: chemotherapy; RT: radiotherapy; ${ }^{*} P<0.05$.

\section{Survival analysis}

During follow-up, 47 patients (62.7\%) had disease progression. The median progression-free survival (PFS) was 9 months. The median survival was 18 months (range: 2-112 months). During follow-up, 30 (40.0\%) patients died of disease, $14(18.7 \%)$ were alive with disease, and $31(41.3 \%)$ were alive without disease.

Univariate analysis showed that the residual disease of SCR, grade, PFI, the largest size of the recurrent tumors, the multiplicity of the recurrent tumors, postoperative therapy after SCR, and ascites were associated with the post-recurrent survival $(P<0.05$, Table 1$)$. The median survival of patients with R0, R1, and R2 were 76.5, 43.8, and 21.8 months, respectively. The differences for stratified comparisons between the outcomes of R0, R1, and R2 were significant (R0 vs. R2: $\chi^{2}=15.55, P=0.00$, R1 vs. R2: $\chi^{2}=5.45, P=0.02$ ) (Figure 1 ). In addition, the differences for stratified comparisons between the outcomes of residual disease of $\leq 1 \mathrm{~cm}$ and $>1 \mathrm{~cm}\left(\chi^{2}=15.55, P=0.00\right)$ were significant. However, there was no significant difference between residual disease of none and $0.1 \sim 1 \mathrm{~cm}$ $\left(X^{2}=0.465, P=0.495\right)$, and there was no significant difference between residual disease of $1-2 \mathrm{~cm}$ and $>2 \mathrm{~cm}$ $\left(X^{2}=1.592, P=0.207\right)$. Therefore, residual disease of $\leq 1 \mathrm{~cm}$ was considered optimal cytoreduction and analyzed in multivariate analyses. The asymptomatic patients with recurrence detected by imaging or CA-125 measurements tended to have shorter survival than patients with recurrence detected by physical examination (44.83 vs.
96 months), but the difference was not significant $(\mathrm{P}=0.134)$. All variables with $P<0.01$ in univariate analysis were analyzed by multivariate analysis, and the results showed that residual disease after SCR and grade were predictive factors for survival after SCR $(P=0.001$ and $P=0.012$, respectively).

\section{Factors associated with the outcomes of SCR}

After SCR, R0 resection was achieved in 43 (57.3\%) patients, R1 in 15 (20.0\%) patients, and R2 in 17 (22.7\%) patients.

In univariate analysis, the age at recurrence, the size of the largest recurrent tumors, the site of recurrence (retroperitoneal or not), and multiplicity of recurrence were associated with optimal cytoreduction (R0 and R1) $(P=0.013,0.022,0.086$, and 0.03 , respectively). Multivariate analysis showed that the age at recurrence, the size of the largest recurrent tumors, and multiplicity of recurrence were associated with the optimal cytoreduction $(P=0.046,0.028$, and 0.044 , respectively) (Table 3 ). Stage at primary surgery, grade, symptoms at recurrence, pathological subtype, PFI, and ascites at recurrence were not predictors of SCR outcomes.

\section{Discussion}

The treatment for recurrent endometrial cancer varies depending on the recurrent location, the extent of disease, and prior therapy used. For patients with a localized vaginal recurrence and no previous irradiation, 
Table 2 Characteristics of recurrence and second debulking surgery

\begin{tabular}{|c|c|}
\hline & Number of patients (\%) \\
\hline \multicolumn{2}{|l|}{ Largest size of recurrence $(\mathrm{cm})$} \\
\hline Median (range) & $6(1-25)$ \\
\hline \multicolumn{2}{|l|}{ Sites of recurrence } \\
\hline Central pelvic-vaginal & $6(8.0)$ \\
\hline Pelvic & $25(33.3)$ \\
\hline Intro-abdorminal alone & $3(4.0)$ \\
\hline Retroperitoneal alone & $8(10.7)$ \\
\hline Pelvic and intra-abdominal & $17(22.7)$ \\
\hline Pelvic and retroperitoneal & $3(4.0)$ \\
\hline Intra-abdominal and retroperitoneal & $1(1.3)$ \\
\hline Vaginal & $5(6.7)$ \\
\hline Inguinal & $5(6.7)$ \\
\hline Abdominal wall & $1(1.3)$ \\
\hline Lung & $1(1.3)$ \\
\hline Ascites & $8(10.5)$ \\
\hline \multicolumn{2}{|l|}{ Multiplicity of recurrence } \\
\hline Solitary & $35(46.7)$ \\
\hline Multiple & $40(53.3)$ \\
\hline \multicolumn{2}{|l|}{ Surgical procedures } \\
\hline Tumor mass resection & $36(51.4)$ \\
\hline Pelvic lymph node resection & $12(16.0)$ \\
\hline Para-aortic lymph node resection & $10(13.3)$ \\
\hline Inguinal lymph node resection & $4(5.3)$ \\
\hline Omentectomy & $17(22.7)$ \\
\hline Appendectomy & $9(12.0)$ \\
\hline Mesenterectomy & $5(6.7)$ \\
\hline Large-bowel resection & $19(25.0)$ \\
\hline Small-bowel resection & $6(8.0)$ \\
\hline Colostomy & $6(8.0)$ \\
\hline Patial abdominal wall resection & $3(4.0)$ \\
\hline Upper vaginectomy & $18(24.0)$ \\
\hline Vulvectomy & $1(1.3)$ \\
\hline Partial urethrectomy & $1(1.3)$ \\
\hline Partial cystectomy and ureterectomy & $2(2.7)$ \\
\hline Ureteral stents & $6(8.0)$ \\
\hline Partial gastrectomy & $1(1.3)$ \\
\hline Radical pulmonary lobe resection & $1(1.3)$ \\
\hline Biopsy alone & $4(5.3)$ \\
\hline \multicolumn{2}{|l|}{ Operative time (minutes) } \\
\hline Median (range) & $150(30-430)$ \\
\hline Blood transfusion & $42(56.0)$ \\
\hline Median (range, blood unit) & $2(1-13)$ \\
\hline Median hospitalized day & $20(6-130)$ \\
\hline
\end{tabular}

Table 2 Characteristics of recurrence and second debulking surgery (Continued)

\begin{tabular}{lc}
\hline Residual disease $(\mathrm{cm})$ & \\
None & $43(57.3)$ \\
$0.1 \sim 1$ & $15(20.0)$ \\
$1 \sim 2$ & $6(8.0)$ \\
$>2$ & $11(14.7)$ \\
Complications & $9(12.0)$ \\
Iliac artery injury & $1(1.33)$ \\
Ureteral injury & $2(2.67)$ \\
Acute renal failure & $1(1.33)$ \\
Urethrovaginal fistula & $1(1.33)$ \\
Bowel obstruction & $1(1.33)$ \\
Deep vein thrombosis & $1(1.33)$ \\
Drug allergy & $1(1.33)$ \\
Hydronephrosis & $1(1.33)$ \\
\hline
\end{tabular}

radiation therapy could provide a long-term pelvic control and 5-year survival rate of $31-53 \%[12,13]$. The majority of patients with recurrence are treated with palliative chemotherapy, and/or hormonal therapy. The commonly used chemotherapy included cisplatin, carboplatin, doxorubicin, paclitaxel, and topotecan, with overall response rate ranging from $20 \%$ to $37 \%$ [14-18]. The response rate of hormonal therapy with progestational agents, anti-estrogens, and gonadotropins-releasing hormone analogs are generally low, ranging from $9 \%$ to $16 \%$ [19-21]. Surgical resection for recurrent endometrial cancer has traditionally been limited to a selected group of patients presenting with a central pelvic recurrence within a previously irradiated pelvic field. However, only few patients are candidates for this approach $[5,6]$.

To date, only 4 nonrandomized, retrospective studies have investigated the outcomes of cytoreductive surgery for recurrent endometrial cancer [7-10] (Table 4). A metaanalysis on these 4 studies was performed to determine the use of cytoreductive surgery [22]. Patients undergoing optimal surgical cytoreduction (ranging from $<2 \mathrm{~cm}$ to no gross residual disease) had an overall survival advantage. However, the subset with no gross residual disease (complete surgical cytoreduction) was associated with improved survival [22]. In this study, we confirmed the survival benefit of patients with optimal cytoreduction. In multivariate analysis, residual disease after SCR and grade were found to be the predictive factors for survival after SCR. Especially, residual disease was the strongest survival determinant for recurrent endometrial cancer $(P=0.001)$.

In previous studies, the definition of optimal cytoreduction was $\leq 1 \mathrm{~cm}$ or $\leq 2 \mathrm{~cm}$. In this study, we found that patients with $\leq 1 \mathrm{~cm}$ residual disease had significant 

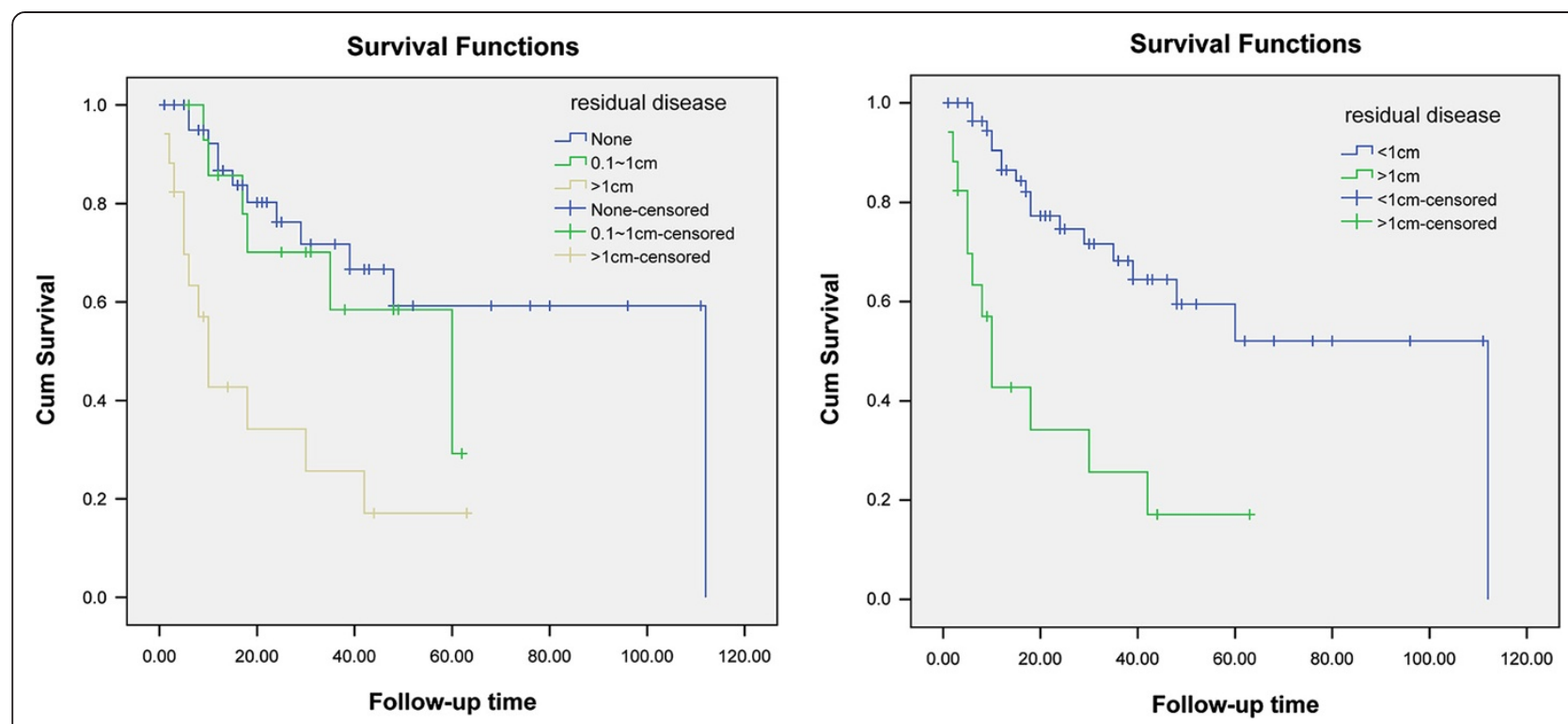

Figure 1 Survival curve of residual disease after second debulking surgery.

survival benefit from cytoreductive surgery, compared with the patients with $>1 \mathrm{~cm}$ residual disease $\left(\chi^{2}=15.55\right.$, $P=0.00)$, while there was no difference in survival between patients with none disease and $0.1-1 \mathrm{~cm}\left(\chi^{2}=0.465\right.$, $\mathrm{P}=0.495)$, and between $1-2 \mathrm{~cm}$ and $>2 \mathrm{~cm}\left(\chi^{2}=1.592\right.$, $\mathrm{P}=0.207)$. Therefore, residual disease of $\leq 1 \mathrm{~cm}$ was considered optimal cytoreduction and pooled together for analysis. These data suggest that the definition of optimal cytoreduction might be $<1 \mathrm{~cm}$, but further studies employing larger samples are needed to confirm this definition.

On the other hand, careful selection of the patients is important due to the complications of SCR. In this study we attempted to predict the optimal cytoreduction. The factors associated with optimal cytoreduction in recurrent endometrial cancer were identified by logistic regression analysis. In univariate analysis, the age, PFI, the size of the largest recurrent tumors, the site of recurrence, and multiplicity of recurrence were associated with optimal cytoreduction, which indicates that patients with younger age, longer PFI, smaller tumor size, and recurrent site not in retroperitoneal, and single recurrence are more likely to achieve optimal cytoreduction. However, in multivariate analysis, only the age, the size of the largest recurrent tumors, and multiplicity of recurrence were associated with the optimal cytoreduction. Therefore, patients with young age ( $<56$ years old), small tumor size $(<6 \mathrm{~cm})$ and solitary recurrence are more likely to achieve optimal cytoreduction and gain benefit.

After SCR, the patients who received radiotherapy after SCR showed better OS than patients with chemotherapy $(p=0.045)$. The reason may be due to the fact that more than half of the patients (48 cases, 64\%) received chemotherapy with widely disseminated tumor, and only 6 patients received radiotherapy with the disease localized to vagina or vulva. However, adjuvant therapy did not show significance in multivariate analysis. In a previous study the median survival of symptomatic patients was longer than that of asymptomatic patients (27 vs. 12 months); although the difference was not statistically significant [23]. Consistent with this, we found that the median survival of symptomatic patients was longer than that of asymptomatic patients (65 vs. 54 months), but the difference was not statistically

Table 3 Logistic regression for clinico-pathologic variables associated with residual disease at second debulking surgery

\begin{tabular}{lcccc}
\hline & UV regression & & MV regression \\
\cline { 3 - 5 } & $\boldsymbol{P}$ value & $\boldsymbol{P}$ value & Exp (B) & 95.0\% Cl \\
\hline Age at second surgery $(>56$ years) & $0.013^{*}$ & $0.046^{*}$ & 3.841 & $1.026-14.381$ \\
Sites of recurrence (multiple) & $0.030^{*}$ & $0.044^{*}$ & 4.061 & $1.039-15.868$ \\
Largest size of recurrence $(>6 \mathrm{~cm})$ & 0.022 & $0.028^{*}$ & 4.611 & $1.180-18.016$ \\
Site of recurrence (retroperitoneal) & 0.086 & 0.156 & 3.027 & $0.656-13.955$ \\
\hline
\end{tabular}


Table 4 Summary of studies on cytoreductive surgery of recurrent endometrial cancer

\begin{tabular}{|c|c|c|c|c|c|c|c|c|}
\hline & Case & $\begin{array}{l}\mathrm{PFI} \\
(\mathrm{m})\end{array}$ & $\begin{array}{l}\text { Surgery } \\
\text { patients }\end{array}$ & $\begin{array}{l}\text { OS } \\
(\mathrm{m})\end{array}$ & $\begin{array}{c}\text { Optimal definition } \\
(\mathrm{cm})\end{array}$ & $\begin{array}{c}\text { Optimal } \\
\text { cytoreduction (\%) }\end{array}$ & $\begin{array}{c}\text { Optimal median } \\
\text { OS }(\mathrm{m})\end{array}$ & $\begin{array}{c}\text { Suboptimal median } \\
\text { OS }(\mathrm{m})\end{array}$ \\
\hline Scarabelli [7] & 20 & 16.9 & 20 & NA & No gross & $65(13 / 20)$ & 12 & Undefined \\
\hline Campagnutta [8] & 75 & 13 & 75 & 19 & $<=1$ & 74.7 (56/75) & 53 & 9 \\
\hline \multirow[t]{2}{*}{ Bristow [9] } & 61 & 18.5 & 35 & 28 & No grossly visible & $65.7(23 / 35)$ & 39 & 13.5 \\
\hline & & / & 26 & 13 & / & / & / & / \\
\hline Awtrey [10] & 27 & 20 & 27 & 35 & $<=2$ & $67(18 / 27)$ & 43 & 10 \\
\hline This study & 75 & 18 & 75 & 18 & $<=1$ & $77.3(58 / 75)$ & 72 & 22 \\
\hline
\end{tabular}

Note. NA, not assessable. PFI, progression free interval. OS, overall survival.

significant $(\mathrm{P}=0.723)$. In addition, we found that patients with recurrence detected by imaging or CA- 125 measurements tended to have shorter survival than patients with recurrence detected by physical examination (44.83 vs. 96 months), but the difference was not significant $(\mathrm{P}=0.134)$. Therefore, early detection of recurrence by imaging and CA-125 measurements can not improve prognosis. Routine follow-up for these patients is necessary to detect recurrence by physical examination.

A dramatic survival advantage of SCR was observed in carefully selected patients. However, due to the radical procedures involved, the incidence of major surgical complications and deaths should be concerned. According to the literatures, the rate of complications varied from $25 \%$ to $62.7 \%$ (Table 5) [7-10]. In our study, total 9 patients (12.0\%) developed perioperative complications, including 1 iliac artery injury, 2 ureteral injury, 1 acute renal failure, 1 urethrovaginal fistula, 1 bowel obstruction, 1 deep vein thrombosis, 1 hydronephrosis, and 1 drug allergy, while 42 patients (56\%) received blood transfusion during surgery. No patient died during perioperative period. The rate of complication in our study was similar to previous studies with blood transfusion included. Therefore, SCR was safe and acceptable in general, but the incidence of severe complications should be concerned. One study reported two (10\%) perioperative deaths after 21 and 30 days, one of them had a history of cerebrovascular and hypertensive disease and developed postoperative hemorrage which required reintervention within $18 \mathrm{~h}$ of surgery [7]. In another study, one patient with diffuse carcinosis died after surgery, whereas five other patients (three with diffuse carcinosis) died in the hospital postoperatively [8]. In this study, four patients with diffuse carcinosis died postoperatively. These data suggest that in patient with carcinosis it is not suitable to perform SCR, and adequate preoperative evaluation is necessary to reduce the rate of perioperative death.

In this study, optimal median OS was significantly longer than that reported in previous studies, but there is no much difference in OS (Table 4). Several reasons may account for it: first, the definition of optimal cytoreduction varied in different studies (ranging from $<2 \mathrm{~cm}$ to no gross residual disease), which influences OS with optimal cytoreduction. Second, the selection of patients is different among different studies. For example, 9 patients who had resection of non-abdominal disease and 13 patients who underwent a pelvic exenterative procedure were excluded in one study [10]. In this study, 4 patients receiving inguinal lymph node resection were included, who had much better OS than patients with abdominal recurrence if optimal cytoreduction was achieved.

There are several limitations of our study. First, the number of patients enrolled in this study is small, due to the infrequency of recurrent endometrial cancer. Therefore, the selection criteria for SCR need to be confirmed in further study. Second, there is a potential for selection bias because our study is retrospective. Prospective study is necessary to identify the appropriate candidates for SCR. Third, we failed to collect the data of the patients who did not undergo cytoreduction and compare them to the patients enrolled in this study, which would strengthen our conclusion that patients with recurrent endometrial cancer would benefit from SCR.

Table 5 Summary of complications of SCR

\begin{tabular}{|c|c|c|c|c|c|}
\hline & Cases & Complications & Patients with BT & BT unit & Perioperative deaths \\
\hline Scarabelli [7] & 20 & $3(15 \%)$ & Not known & $1.8(0-5)$ & $2(10 \%)$ \\
\hline Campagnutta [8] & 75 & $23(30.7 \%)$ & Not known & $1.3(0-8)$ & $1(1.3 \%)$ \\
\hline Bristow [9] & 35 & $13(37.1 \%)$ & $10(28.6 \%)$ & $3(1-6)$ & None \\
\hline Awtrey [10] & 27 & $17(62.7 \%)$ & $9(33.3 \%)$ & Not known & None \\
\hline This study & 75 & $9(12 \%)$ & $42(56 \%)$ & $2(1-13)$ & None \\
\hline
\end{tabular}

Note. BT, Blood transfusion. 


\section{Conclusions}

Based on our data, we get the following conclusions. First, patients with residual disease less than $1 \mathrm{~cm}$ could benefit from optimal SCR with prolonged overall survival. Second, patients should be carefully selected before the surgery, as patients with younger age, tumor size less than $6 \mathrm{~cm}$, and single recurrence are more likely to achieve satisfied cytoreduction. Third, complications of SCR are not common but should be considered.

\section{Competing interests}

The authors declare that they have no competing interests.

\section{Authors' contributions}

YR and BS performed the study. DS performed statistical analysis. HW conceived the study. All authors read and approved the final manuscript.

\section{Acknowledgements}

The study was funded by Ministry of Education of China (No. 20110071120099). We appreciate the help of Prof. Rongyu Zang and Prof. Xiaohua Wu in the writing of the manuscript, and Prof. Ziting Li in data collection. The funders had no role in study design, data collection and analysis, decision to publish, or preparation of the manuscript.

\section{Author details}

'Department of Gynecologic Oncology, Fudan University Shanghai Cancer Center, Shanghai 200032, China. ${ }^{2}$ Department of Oncology, Shanghai Medical College, Fudan University, Shanghai 200032, China. ${ }^{3}$ Department of Pathology, Fudan University Shanghai Cancer Center, Shanghai 200032, China.

Received: 12 November 2013 Accepted: 19 February 2014

Published: 26 February 2014

\section{References}

1. Fung-Kee-Fung M, Dodge J, Elit L, Lukka H, Chambers A, Oliver T: Follow-up after primary therapy for endometrial cancer: a systematic review. Gynecol Oncol 2006, 101(3):520-9.

2. Aalders J, Abeler $\mathrm{V}$, Kolstad P: Recurrent adenocarcinoma of the endometrium: a clinical and histopathological study of 379 patients. Gynecol Oncol 1984, 17(1):85-103.

3. Wylie J, Irwin C, Pintilie M, Levin W, Manchul L, Milosevic M, Fyles A: Results of radical radiotherapy for recurrent endometrial cancer. Gynecol Oncol 2000, 77(1):66-72.

4. Jereczek-Fossa B, Badzio A, Jassem J: Recurrent endometrial cancer after surgery alone: results of salvage radiotherapy. Int J Radiat Oncol Biol Phys 2000, 48(2):405-13

5. Morris M, Alvarez RD, Kinney WK, Wilson TO: Treatment of recurrent adenocarcinoma of the endometrium with pelvic exenteration. Gynecol Oncol 1996, 60(2):288-91.

6. Barakat RR, Goldman NA, Patel DA, Venkatraman ES, Curtin JP: Pelvic exenteration for recurrent endometrial cancer. Gynecol Oncol 1999, 75(1):99-102.

7. Scarabelli C, Campagnutta E, Giorda G, DePiero G, Sopracordevole F, Quaranta M, DeMarco L: Maximal cytoreductive surgery as a reasonable therapeutic alternative for recurrent endometrial carcinoma. Gynecol Oncol 1998, 70(1):90-3

8. Campagnutta E, Giorda G, De Piero G, Sopracordevole F, Visentin MC, Martella L, Scarabelli C: Surgical treatment of recurrent endometrial carcinoma. Cancer 2004, 100(1):89-96

9. Bristow RE, Santillan A, Zahurak ML, Gardner GJ, Giuntoli RL 2nd, Armstrong DK Salvage cytoreductive surgery for recurrent endometrial cancer. Gynecol Oncol 2006, 103(1):281-7.

10. Awtrey CS, Cadungog MG, Leitao MM, Alektiar KM, Aghajanian C, Hummer AJ Barakat RR, Chi DS: Surgical resection of recurrent endometrial carcinoma. Gynecol Oncol 2006, 102(3):480-8.

11. Pecorelli S: Revised FIGO staging for carcinoma of the vulva, cervix, and endometrium. Int J Gynaecol Obstet 2009, 105(2):103-4.
12. Curran WJ, Whittington R, Peters AJ, Fanning J: Vaginal recurrences of endometrial carcinoma: the prognostic value of staging by a primary vaginal carcinoma system. Int J Radiat Oncol Biol Phys 1988, 15(4):803-8

13. Sears JD, Greven KM, Hoen HM, Randall ME: Prognostic factors and treatment outcome for patients with locally recurrent endometrial cancer. Cancer 1994, 74(4):1303-8.

14. Wadler S, Levy DE, Lincoln ST, Soori GS, Schink JC, Goldberg G: Topotecan is an active agent in the first-line treatment of metastatic or recurrent endometrial carcinoma: Eastern Cooperative Oncology Group study E3E93. J Clin Oncol 2003, 21(11):2110-4.

15. Lincoln S, Blessing JA, Lee RB, Rocereto TF: Activity of paclitaxel as second-line chemotherapy in endometrial carcinoma: a Gynecologic Oncology Group study. Gynecol Oncol 2003, 88(3):277-81.

16. Burke TW, Munkarah A, Kavanagh JJ, Morris M, Levenback C, Tornos C, Gershenson DM: Treatment of advanced or recurrent endometrial carcinoma with single-agent carboplatin. Gynecol Oncol 1993, 51(3):397-400.

17. Thigpen JT, Blessing JA, Homesley H, Creasman WT, Sutton G: Phase II trial of cisplatin as first-line chemotherapy in patients with advanced or recurrent endometrial carcinoma: a Gynecologic Oncology Group study. Gynecol Oncol 1989, 33(1):68-70.

18. Fleming GF, Brunetto VL, Cella D, Look KY, Reid GC, Munkarah AR, Kline R, Burger RA, Goodman A, Burks RT: Phase III trial of doxorubicin plus cisplatin with or without paclitaxel plus filfrastim in advanced endometrial carcinoma: a Gynecologic Oncology Group study. J Clin Oncol 2004, 22(11):2159-66.

19. Thigpen T, Brady MF, Homesley HD, Soper JT, Bell J: Tamoxifen in the treatment of advanced or recurrent endometrial carcinoma: a Gynecologic Oncology Group study. J Clin Oncol 2001, 19(2):364-7.

20. Asbury RF, Brunetto VL, Lee RB, Reid G, Rocereto TF: Goserelin acetate as treatment for recurrent endometrial carcinoma: a Gynecologic Oncology Group study. Am J Clin Oncol 2002, 25(6):557-60.

21. Fiorica JV, Brunetto VL, Hanjani P, Lentz SS, Mannel R, Andersen W: Phase II trial of alternating courses of Megestrol acetate and tamoxifen in advanced endometrial carcinoma: a Gynecologic Oncology Group study. Gynecol Oncol 2004, 92(1):10-4.

22. Barlin JN, Puri I, Bristow RE: Cytoreductive surgery for advanced or recurrent endometrial cancer: a meta-analysis. Gynecol Oncol 2010 118(1):14-8.

23. Otsuka I, Uno M, Wakabayashi A, Kameda S, Udagawa H, Kubota T: Predictive factors for prolonged survival in recurrent endometrial carcinoma: implications for follow-up protocol. Gynecol Oncol 2010, 119(3):506-10.

doi:10.1186/1471-2407-14-135

Cite this article as: Ren et al:: Salvage cytoreductive surgery for patients with recurrent endometrial cancer: a retrospective study. BMC Cancer 2014 14:135.

\section{Submit your next manuscript to BioMed Central and take full advantage of:}

- Convenient online submission

- Thorough peer review

- No space constraints or color figure charges

- Immediate publication on acceptance

- Inclusion in PubMed, CAS, Scopus and Google Scholar

- Research which is freely available for redistribution 